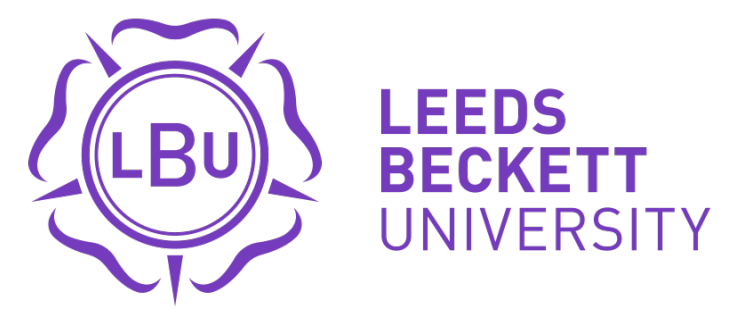

Citation:

Fabri, M and Wall, A and Trevorrow, P (2013) Changing eating behaviors through a cooking-based website for the whole family. Lecture Notes in Computer Science (including subseries Lecture Notes in Artificial Intelligence and Lecture Notes in Bioinformatics), 8014 L (PART 3). pp. 484-493. ISSN 0302-9743 DOI: https://doi.org/10.1007/978-3-642-39238-2_53

Link to Leeds Beckett Repository record:

https://eprints.leedsbeckett.ac.uk/id/eprint/5655/

Document Version:

Article (Accepted Version)

Unsure if we should have this version deposited.

The aim of the Leeds Beckett Repository is to provide open access to our research, as required by funder policies and permitted by publishers and copyright law.

The Leeds Beckett repository holds a wide range of publications, each of which has been checked for copyright and the relevant embargo period has been applied by the Research Services team.

We operate on a standard take-down policy. If you are the author or publisher of an output and you would like it removed from the repository, please contact us and we will investigate on a case-by-case basis.

Each thesis in the repository has been cleared where necessary by the author for third party copyright. If you would like a thesis to be removed from the repository or believe there is an issue with copyright, please contact us on openaccess@leedsbeckett.ac.uk and we will investigate on a case-by-case basis. 


\title{
Changing Eating Behaviors through a Cooking-Based Website for the Whole Family
}

\author{
Marc Fabri $^{1}$, Andrew Wall ${ }^{2}$, Pip Trevorrow ${ }^{1}$ \\ ${ }^{1}$ Leeds Metropolitan University, Leeds, United Kingdom \\ (m.fabri,p.trevorrow)@leedsmet.ac.uk \\ ${ }^{2}$ No Affiliation \\ andy_wall9@hotmail.com
}

\begin{abstract}
This paper reports on the results of a study investigating how nutritional eating behaviors can be improved by presenting a cooking-based website for parents to use with their children. Participants' eating behaviors were closely monitored via questionnaires and food diaries. Results show that over the course of the study, children's willingness to consume fruit and vegetables had improved and they enjoyed participating in food preparation. This was supported by the participants' food diaries, which showed a statistically significant increase in the number of portions of fruit and vegetables consumed by both children and parents. An attempt was made to place participants in a stage of change before and after the study (Transtheoretical Model). This was flawed, however, due to inaccurate measurements and the short study duration. Overall, this study provides support for the use of educational websites, in particular a cooking website, to improve nutritional eating behaviors in children.
\end{abstract}

Keywords: Obesity, Nutrition, Behavior Change, Persuasive Technology

\section{Introduction}

Childhood nutrition has a significant impact on the physical and mental development of children [1]. Developing interventions to improve children's healthy eating behaviors is therefore extremely important and should be researched thoroughly. Consumption of fruit and vegetables during childhood can decrease the risk of many types of cancer [2], cardiovascular disease [3] and stroke [4], as well as diabetes and bowel disorders [5]. Furthermore, the World Health Organisation (WHO) estimated that $70 \%$ of premature deaths in adulthood can be attributed to health related behaviors learned in adolescence [6]. There has been rising concern over the increasing numbers of overweight and obese in the population globally. In developed countries in particular, childhood obesity has been seen to reach epidemic levels [7]. The UK [8] viewed the problem as so severe that they claimed that the current generation of children is the first for over a century whose life expectancy has fallen. It concluded that unless action was taken, by $205060 \%$ of men, $50 \%$ of women and $25 \%$ of children would be obese. Not only this, but also that the numbers of overweight in the population would

adfa, p. 1, 2013.

(C) Springer-Verlag Berlin Heidelberg 2013 
reach approximately $90 \%$ of adults and $66 \%$ of children [9]. Figures such as these have provided the impetus for the British government to develop a number of campaigns to promote healthy eating in people of all ages. These campaigns include "Healthy Weight, Healthy Lives" [10], which is a cross-government strategy to focus on the prevention and management of excess weight, and the "Change4Life" campaign [11]. The Change4Life campaign uses multiple approaches to encourage the improvement of healthy eating and a more active lifestyle. The campaign includes an informative website which features lots of ideas for improving families' diets without increasing costs, tips for lifestyle changes that would complement dietary changes, further details about what campaigns are currently taking place throughout the country and links to national partners. The campaign also features activities that are rolled out into the community at places such as schools and nurseries. For example the Games4Life campaign, which is designed to encourage physical activity in children's' everyday lives, was introduced in June 2012. Another example is the successful MoreLife residential summer camps for overweight and obese children, supported by the British National Health Service [12]. The annual program includes a daily schedule of six one-hour, skill-based, fun, physical activity sessions, moderate dietary restriction, and group-based educational sessions [12]. In a further effort to disseminate information on nutrition to the public, the government have also delivered a series of training courses to nursery and school staff called HENRY (Health, Exercise and Nutrition for the Really Young) [13]. The training not only teaches staff about current government guidelines for nutritional standards such as portion sizes and advised nutritional intake, but also how to best convey this information to community members. This approach emphasizes the need to help parents come to the appropriate conclusions themselves rather than bombarding them with information, thereby giving them the knowledge and skills to reach such conclusions without any help in the future [13].

\section{$2 \quad$ Healthy Eating Behaviors}

Research suggests that the primary focus of improving healthy eating behaviors should be upon children rather than adults. Obesity is difficult to reverse in adults and even older children [14]. Taveras et al [15] extended this by suggesting that healthy eating strategies should begin as early as possible, preferably when feeding practices are just beginning. Similarly, it has been found that people will continue to eat foods that they ate as children throughout their lives [16]. This was mirrored in a longitudinal study of food intake which found that children who selected the least healthy foods at the beginning of the study continued to do so throughout the study [17]. Lytle et al [18] examined eating patterns in children in American elementary, junior high and middle schools. Interestingly, they found that the consumption of breakfast, fruit, vegetables and milk decreased with increasing age. For example, fruit consumption decreased by $41 \%$ between the 3rd and 8th grades, whilst vegetable consumption decreased by $25 \%$ and the amount of soft drinks consumed more than tripled. These startling results prompted the authors to highlight the need for promotion of healthy eating behaviors both at home and at school, particularly in adolescents [19]. 


\subsection{The Importance Of Parental Involvement.}

The influence that parents have on their children's diet has been displayed by many researchers. Olivera et al [20] performed a study examining the food intake of preschool children and their parents concluding that parents should be the target of interventions attempting to change their children's diets. Story et al [21] found that parental practices and foods available at home were strongly influential in the dietary decisions of children. Lindsay et al [22] described parental influence as the most important influence on a child's healthy eating behavior, and that understanding the variety of influences the parent has is key to preventing poor healthy eating behaviors. This conclusion was also reached elsewhere [14] following a systematic review of interventions that target parents. In their critique they suggested that it is an area of research that is still in its infancy, but shows promise as an obesity prevention strategy. There is much research that provides evidence for the need to target childhood health through their parents. For example, a relationship was found between the quality of children's diets and their mother's health motivation [23]. Another interesting finding was that mothers did not necessarily eat the same food as their children [24]. Perhaps encouraging parents and children to eat together and to eat the same food would motivate more healthy eating behaviors. Further, children of adolescent age were found to be more likely to eat breakfast if their parents did too [25].

\subsection{Using Websites To Modify Eating Behavior}

Such a large proportion of the UK population, in fact $77 \%$ of households as of August 2011, now has access to the internet that it must be considered as a viable method of disseminating information [26]. Clark et al [27] developed a website used to disseminate information to childcare providers about feeding infants. Participants used the website for a 3 month period, completing surveys on knowledge of and attitudes towards nutrition before and after using the site. Results showed that both knowledge of and attitudes towards infant nutrition improved, but not to a statistically significant extent. The authors conceded that this may have been due to the extremely basic nature of the website. In the United States, the First Lady Michelle Obama's Let's Move initiative [28] is a coordinated strategy to significantly reduce childhood obesity within a generation. It combines legislative efforts with advice on the Let's Move website and affiliated sites, offering parents advice with nutrition facts, recipes, and step-bystep action plans. However, it is mainly targeted at parents and it is too early to assess the impact of the initiative.

Our aim in the current study was to employ a fun and engaging user experience in an attempt to produce significant positive behavior change results. In particular, we considered images children would respond to as central to the experience. The use of images in learning and behavior acquisition has been found to have a positive effect, and there is a particular prevalence in the use of images in software aimed at children [15]. Research on using websites to disseminate nutritional information is still in its early stages, and more research is required to determine whether this is the most ap- 
propriate method of disseminating such information, particularly given the rise of mobile apps. In the present study, it is hoped that using a website as a behavior intervention will influence eating behaviors of participants for the better, i.e. they eat more healthy fruit and vegetables. From the discussed research, it is clear that instilling these behaviors early in life is vital in ensuring their presence and maintenance later in life. Therefore the website to be used in this study will be aimed at parents and their young children.

\section{Transtheoretical Model of Change}

This study uses the Transtheoretical Model (TTM) of behavior change as a basis for assessing participants' healthy eating behaviors. TTM has been used extensively to develop interventions which can be tailored to the individual's stage of readiness to change an unhealthy behavior or to adopt healthy lifestyle behaviors [29-30]. The TTM focuses on understanding how behavior changes, asserting that individuals move through 5 distinct stages of behavior change [30]:

1. The individual having no intention to change the behavior within the next 6 months (pre-contemplation stage).

2. They would move to the contemplation stage upon intending to change their behavior within the next 6 months.

3. When the individual has a serious intention to change the behavior within the next 30 days they are in the preparation stage.

4. The action stage is marked by engaging in the behavior change at the target level for 6 months or less.

5. Once this behavior change has been sustained for more than 6 months, the individual has reached the maintenance stage.

Before reaching the final stage individuals will often move through the five stages in a cyclical fashion [31] due to relapses of behavior whereby the individual could reenter the cycle at any of the prior stages.

\section{Website Prototype}

Building on the research and government initiatives outlined above, the study reported in this paper had the overall aim to investigate whether regular usage of a cookingbased website can improve nutritional eating behaviors. The website was designed for both children and their parents to encourage healthy eating behaviors for the whole family. It contains content related to cooking and nutrition including a blog with recipes, cook-a-long videos, specially featured meals, a forum for users to discuss nutrition-based issues, information on healthy eating and links to related websites. The main tool for delivering the content and engaging users is a cuddly toy bear called Noodles. Users of the website can also find out more about the Noodles character and its back story. The decision to introduce a toy character was based on previous re- 
search which stated the importance of including a 'fun factor' in systems for children [32] as well as the 'Computers As Social Actors' (CASA) model [33-34]. CASA presumes that interfaces supported by toy characters can make technology interactions simpler and more intuitive because they are built on implicit social understandings that users already have, and hence require no extra learning or accommodation [34]. This is particularly the case for young children, who due to their stage of development generally have cognitive and motor limitations [35].

Page layout, design and richness of experience was somewhat restricted by the site's prototype nature. Figure 1 shows the homepage with navigation, image carousel, Noodles' back story and the recipe blog further down the page. The main aim of the research was to create a proof-of-concept, whilst visual design of the website is an area worthy of future consideration and research.

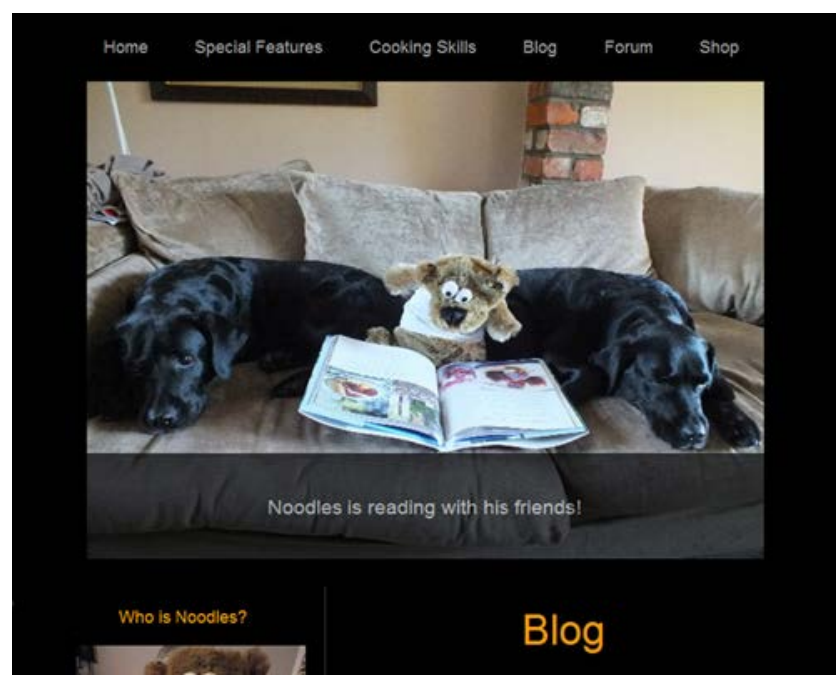

Figure 1: Website Homepage

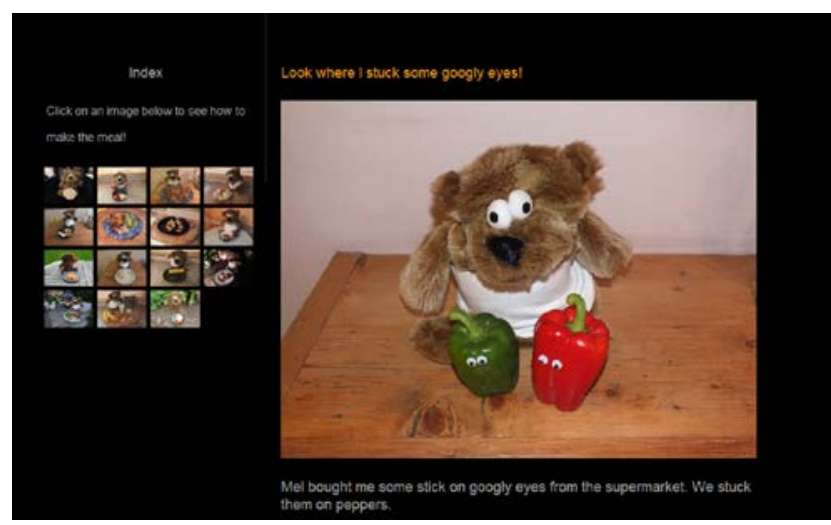

Figure 2: Recipe blog entry and index of recipes on the left 


\section{$5 \quad$ Study Details}

The study employed qualitative and quantitative methods to investigate changes in participants' healthy eating behaviors before and after using the website.

\subsection{Procedure}

Participants were recruited via opportunity sampling. Altogether 7 mothers between the age of 40 and 47 took part. Children were in the age range 5-11, attending one of three different schools. All mothers were provided with an information sheet on the investigation and gave their informed consent to participate. The sample size is small and this was due to the time of the study - during the school summer holidays. Study duration varied from participant to participant. The shortest was 17 consecutive days, the longest 20 consecutive days. Given the small number of participants available to take part in this study and the potential complexity of eating behaviors, semistructured interviews were deemed the most appropriate method of gathering rich data. Semi-structured interviews utilize a fixed set of core questions to be covered whilst enabling the interviewee to provide clarification or elaboration on any issues that may be relevant to the study [36], thereby providing flexibility.

Participants took part in a pre-intervention semi-structured interview to provide both quantitative and qualitative data on initial eating habits. Any barriers perceived by participants to limit nutritional eating behaviors could be investigated, as well as the willingness of both parents and children to eat fruit and vegetables. The interview also involved participants completing a questionnaire to identify which TTM stage of change each participant was in at the time. The questionnaire, previously used by Green et al [30], included items that mapped directly to one of the TTM stages. The same interview structure used post-intervention so that a comparison could be made to assess any apparent changes. Additionally, the post-intervention interview contained a set of questions related to website content and usability. Interviews were transcribed and any differences in answers between the two interviews were noted. During the intervention period participants completed food diaries by recording meals and detailing the numbers of portions of fruit and vegetables consumed, to the nearest half portion. Diaries were completed on a particular weekday, once a week This frequency was regarded as the most accurate and most practical alternative to observing participants 24/7. Participants were encouraged to make records of foods consumed immediately after each meal to minimize erroneous or missing entries.

\subsection{Interview Results}

The pre and post-intervention interviews suggest that the intervention had a positive effect on participants' attitudes to healthy eating. All participants reported that the use of the website had made their children keener and more willing to cook with them and try new foods, but participants did not explicitly state that they had been eating more healthily in this period. 
The majority of parents were always willing to consume fruit and vegetables, but in reality there were varying degrees of actual healthy eating behaviors. The most common reported barrier was time restrictions related to working patterns. However, participants were generally interested in their children's healthy eating behavior and seemed to make more of an effort to get their children to eat more healthy foods following the study. The amount of meals participants and their children ate together varied greatly, both between participants and on different days or times of year for each participant. Somewhat predictably, this was directly related to children's school hours. Whether participants ate the same meals as their children also varied, with some eating the same meals but later than their children, or, as one participant reported, only eating what their child leaves on their plate. These behaviors remained unchanged during the intervention period, and appeared to be derived from longstanding habits and routines. Most participants reported a gradual introduction of new recipes, attempting to find new foods that their children enjoyed. Some very actively changed their family's diet. One participant who did report making an active change stated that whilst it was difficult at first, it became much easier once a routine was established.

\subsection{TTM Stages}

Figure 3 shows the stages of the TTM that participants were considered to be in at the pre and post-intervention interviews. Two of the seven participants progressed forwards along TTM stages, while one participant stayed at the same stage and four participants moved backwards:

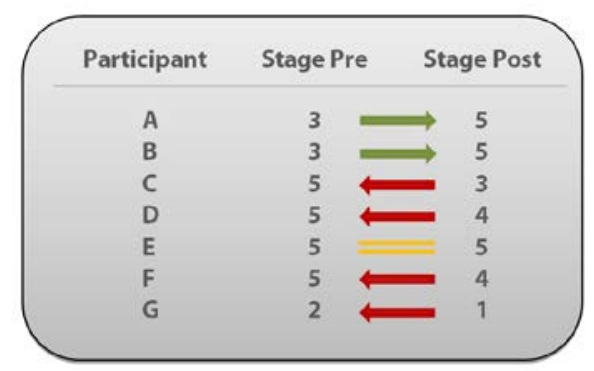

Figure 3: TTM stage change by participant

These results were surprising, and suggest potential issues with the questionnaire and participants' judgement of their own fruit and vegetable consumption. For example, participants A and B moved from stage 3 (preparation) to stage 5 (maintenance), a behavior change that normally takes at least 12 months. Participants D and F moved backwards, which is possible but unlikely, especially in the short time period. The questionnaire, or rather the inferences taken from self-reported consumption with regards to TTM stages, are clearly flawed and require further attention. 


\subsection{Food Diaries}

Participants were asked to complete a food diary on one day, once a week. Some participants completed their diary entries once at the beginning and once at the end of the intervention period. Therefore, to ensure consistency across all participants, we considered only the first and last entry of each food diary. Overall, participants' fruit and vegetable consumption increased during the intervention. This was the case for parents as well as children. $11 \%$ of participants reported consumption of their 5 -a-day before the intervention, compared to $26 \%$ after the intervention. The overall change to healthy eating behavior was statistically significant $(\mathrm{P}(\mathrm{T}<=\mathrm{t})$ two-tail, $\mathrm{p}=0.004)$.

\subsection{Website Evaluation}

The website was generally well received. All participants reported enjoying using it, as did their children. The majority of users found the website easy to use (100\%) and navigate (71.4\%). Two participants commented on the text content and wording being particularly child friendly. Participants liked the look and feel of the website, although many suggested decreasing the size of food images. The primary character 'Noodles' was highlighted as being particularly beneficial, as was the inclusion of people in the photos alongside the character, which helped make Noodles seem real. One participant specifically highlighted how the website was a "fun way of getting children interested in cooking", and that it was better than other cooking games or websites their children have used before. Regarding previous experience, all participants reported being generally computer literate and confident in using the Internet. Many use the Internet to find recipes, and all but one of the participants said they would be using the study's website more in the future for this purpose.

\section{Discussion}

Results from the food diaries showed a statistically significant increase in healthy food consumption, thereby meeting the main objective of the investigation. Interestingly, participants did not think their behavior had changed significantly when asked about this during the interviews. One aspect that emerged from the interviews was that participants generally saw themselves as willing to eat healthily. This increased during the trials as did participants' interest in trying out new foods. This is somewhat in line with previous findings that parental practices and foods available at home were strongly influential in the dietary decisions of children [21]. However, perceived barriers (such as time constraints) prevented participants from eating as much healthy food as they would have liked. Despite this, participants ensured that their children ate as many portions of fruit and vegetables as possible, confirming the suggestion that mothers perceived their child's health to be more important than their own [37].

There is clearly a tension here between parents wanting their children to eat more healthily than they might do themselves, whilst children are being directly influenced by their parents' eating habits. This can be further exacerbated by parents not having 
meals together with their children. We therefore propose that it is most effective for future interventions to involve children and parents collaboratively, thereby maximizing sustained dietary improvements for both. In addition to the motivational and nutritional benefits of 'doing it together', there is a third factor: children very much enjoyed engaging in the joint activity with their parents, and this may prove equally influential in improving, and sustaining, healthy eating behaviors.

The results of placing the participants in stages of the Transtheoretical Model of health behavior change did not support the rest of the study findings. The findings indicated that more than half of participants moved backwards in their TTM stage during the intervention. However, as pointed out previously, some of the stage movements were deemed highly unlikely given the time period involved. More attention needs to be paid to how participants approach self-reporting, and how this data is then used to place the participant in a TTM stage.

It should be noted that the use of quantitative data as well as qualitative data gave a better understanding of the results than either would have alone. The results from the interviews and food diaries did not always match up though, and whilst some of the data had been regarded as unreliable (for example the TTM stage placement), as a whole the combination of the two has led to a better understanding of the effects of the website as an intervention in healthy eating behaviors.

\section{Further Work}

This project has certainly opened up suggestions for further research. The intervention website could be expanded to cover additional aspects of eating behavior - something participants suggested in their feedback. These may include sections to increase knowledge on nutrition and related quizzes, questionnaires or games, previously put forward as directly affecting nutritional behaviors [38], and a questionnaire similar to that used by Oenema et al [39] so participants can assess their own healthy eating behaviors in a personalized system. Future work may also focus on educating parents in quick and healthy meals to combat the perceived time constraints. The scope of the research itself could be expanded to incorporate more detailed investigations of behavioral aspects like attitudes towards healthy eating and social aspects that affect the number of portions of fruit and vegetables consumed. Factors like these should be investigated through a more thorough set of interview questions.

Finally, we are interested in creating a mobile app version of the site, focusing on personalized content and the use of persuasive strategies where the device becomes a social companion. We believe that the 'always on' and 'always connected' nature of mobile devices make them an ideal technology to support individuals during all stages of behavior change. 


\section{References}

1. Shor, R., Friedman, A.: Integration of nutrition-related components by early childhood education professionals into their individual work with children at risk. Early Child Development and Care 179(4), 477-486 (2009)

2. World Cancer Research Fund: Food nutrition and the prevention of cancer: A global perspective. American Institute for Cancer Research, Washington (1997)

3. Liu, S., Melanson, J., Lee, I., Cole, S., Hennekins, H., Willett, W., Furing, J.: Fruit and vegetable intake and the risk of cardiovascular disease. J Clin. Nutr. 72, 922-928 (2000)

4. Joshipura, K. J., Ascherio, A., Manson, J. E., Stampfer, M. J., Rimm, E. B., Speizer, F. E., Hennekens, C. H., Spiegelman, D., Willett, W. C.: Vegetable and fruit intake in relationship to ischemic stroke. JAMA 282, 1233-1239 (1999)

5. Gregory, J.: National Diet and Nutrition Survey. Vol 1, HMSO, London (2000)

6. World Health Organization: The Second Decade: Improving Adolescent Health and Development, http://whqlibdoc.who.int/hq/1998/WHO_FRH_ADH_98.18_Rev.1.pdf

7. Foley, L., Maddison, R.: Use of Active Video Games to Increase Physical Activity in Children: A (Virtual) Reality? Pediatric Exercise Science 22(1), 7-20 (2010)

8. House of Commons Health Committee: Obesity. Stationery Office, London (2004)

9. Department of Health: Obesity, http://www.dh.gov.uk/en/Publichealth/Obesity/index.htm

10. Department for Children, Schools and Families: Healthy Weight, Healthy Lives. HMSO, London (2010)

11. Department of Health: Change 4 Life, http://www.nhs.uk/change4life

12. Gately, P., Cooke, C., Barth, J., Bewick, B., Radley, D., Hill, A.: Children’s Residential Weight-Loss Programs Can Work: A Prospective Cohort Study of Short-Term Outcomes for Overweight and Obese Children. Pediatrics 116(1), 73 -77 (2005)

13. HENRY: Health Exercise Nutrition for the Really Young. http://www.henry.org.uk

14. Skouteris, H., McCabe, M., Swinburn, B., Newgreen, V., Sacher, P. Chadwick, P.: Parental Influence and Obesity Prevention in Pre-Schoolers. Obesity Review 12, 315-328 (2011)

15. Taveras, E.M., Gillman, M. W., Kleinman, K., Rich-Edwards, J. W., and Rifas-Shiman, S. L.: Racial/Ethnic Differences in Early-Life Risk Factors for Childhood Obesity. Pediatrics 125(4), 686-695 (2010)

16. Steptoe, A., Pollard, T., Wardle, J.: Development of a Measure of the Motives Underlying the Selection of Food: The Food Choice Questionnaire. Appetite 25, 267-84 (1995)

17. Kelder, S., Perry, C., Klepp, K. I., Lytle, L.: Longitudinal tracking of adolescent smoking, physical activity and food choice behaviors. Am. J. Publ. Health 84, 1121-1126 (1994)

18. Lytle, L. A., Seifert, S., Greenstein, J., McGovern, P.: How Do Children's Eating Patterns and Food Choices Change Over Time? Am. J. Health Promotion 14(4), 222-228 (2000)

19. Ells, L. J., Campbell, K., Lidstone, J., Kelly, S., Lang, R., Summerbell, C.: Prevention of Childhood Obesity. Clinical Endocrinology \& Metabolism, 19(3), 441-454 (2005)

20. Olivera, S. A., Ellison, R. C., Moore, L. L., Gillman, M. W., Garrahie, E. J. Singer, M. R.: Parent-Child Relationships in Nutrient Intake. Am. J. Clinical Nutr. 56, 593-598 (1992)

21. Story, M., Neumark-Sztainer, D., French, S.: Individual and Environmental Influences on Adolescent Eating Behaviors. J. Am. Dietetic Assoc. 102S(3) (2002)

22. Lindsay, A. C., Sussner, K. M., Kim, J., Gortmaker, S.: The Role of Parents in Preventing Childhood Obesity. Future of Children 16(1), 169-186 (2006)

23. Contento, I. R., Basch, C., Shea, S., Gutin, B., Zybert, P., Michela, J. L., Rips, J.: Relationship of Mothers' Food Choice Criteria to Food Intake of Pre-School Children: Identification of Family Subgroups. Health Education Quarterly 20, 243-59 (1993) 
24. Alderson, T., Ogden, J.: What Mothers Feed Their Children and Why. Health Education Research: Theory and Practice 14, 717-727 (1999)

25. Pearson, N., Biddle, S. J. and Gorely, T.: Family Correlates of Breakfast Consumption Among Children and Adolescents: A Systematic Review. Appetite 52(1), 1-7 (2009)

26. Office For National Statistics: Internet Access - Households and Individuals 2011, http://www.ons.gov.uk/ons/dcp171778_227158.pdf

27. Clark, A., Anderson, J., Adams, E., Baker, S., Barrett, K.: Assessing an Infant Feeding Web Site as a Nutrition Education Tool for Child Care Providers. J Nutr. Educ. \& Behavior 41(1), 41-46 (2009)

28. Let's Move: America's Move to Raise a Healthier Generation of Kids, http://www.letsmove.gov

29. Prochaska, J. O., Redding, C. A. and Evers, K. A.: The transtheoretical model and stages of change. In: Glanz, K., Rimer, B. K. and Lewis, F. M. (eds.) Health Behavior and Health Education, 60-84, Jossey-Bass, San Francisco (2002)

30. Green, G. W., Fey-Yensan, N., Padula, C., Rossi, S., Rossi, J. S. and Clark, P. G.: Differences in Psychosocial Variables by Stage of Change for Fruits and Vegetables in Older Adults. J. Am. Diet Assoc. 104, 1236-1243 (2004)

31. Green, G. W. and Rossi, S. R.: Stages of change for dietary fat reduction over 18 months. J Am. Diet Assoc. 98, 529-534 (1998)

32. Chamberlin, B. A.: Creating Entertaining Games With Educational Content. PhD Thesis, New Mexico State University (2003)

33. Fogg, B. J., Nass, C.: Silicon sycophants: The effects of computers that flatter, Int. J. Human-Computer Studies 46(5), 551-561 (1997)

34. Fogg, B. J.: Persuasive Technology. Morgan Kaufmann, San Francisco (2003)

35. Bergman,E: Information appliances and beyond. Morgan Kaufmann, San Francisco (2000)

36. Becker, H.: Tricks of the Trade: How to Think About Your Research While You're Doing It. University of Chicago Press, Chicago (1998)

37. Wardle, J.: Parental Influences on Children's Diets. Proceedings of the Nutrition Society 54, 747-58 (1995)

38. Van Horn, L., Obarzanek, E., Friedman, L. A., Gernhofer, N., Barton, B.: Children's adaptations to a fat-reduced diet. Pediatrics 115 (6), 1723-1733 (2005)

39. Oenema, A., Brug, J., Lechner, L.: Web-based technology tailored nutrition education: results of a randomized control trial. Health Education Research 16, 647-660 (2001) 